Editorial

\title{
Through the lens of health disparities research
}

\section{Through the lens of health disparity research}

Disparities in health and health care have been a longstanding challenge in the United States resulting in differing degrees of quality and access to health care and poorer health outcomes. While "health" and "health care" are often used interchangeably, there are not synonymous terms. A "health disparity" refers to a higher burden of disease, disability, or mortality experienced by socioeconomic and/ or geographically defined population groups. ${ }^{1}$ In contrast, a "health care disparity" refers to distinctions between groups in regards to insurance coverage, access and utilization of care, and quality of care. ${ }^{2}$ More definitively, health and health care disparities refers to differences between groups that is not explained by health care necessity, patient choices, or treatment decisions. In both instances, there exist complex, interrelated factors such as socio-structural conditions, social networks, psychosocial mechanisms, and various

\author{
Volume 2 Issue 5 - 2017
}

Theresa MWadas

Capstone College of Nursing, University of Alabama, USA

Correspondence: Theresa MWadas, Capstone College of Nursing, University of Alabama, USA, Email twadas@ua.edu

Received: April 14, 2017 | Published: May 01, 2017

pathways that impact health. Figure 1 illustrates the complexity, and inter-related facets of upstream and downstream factors of health. ${ }^{3}$ Thus, the lens of health disparity research often encompasses a broad range of dimensions and often requires multidisciplinary teams to solve them.

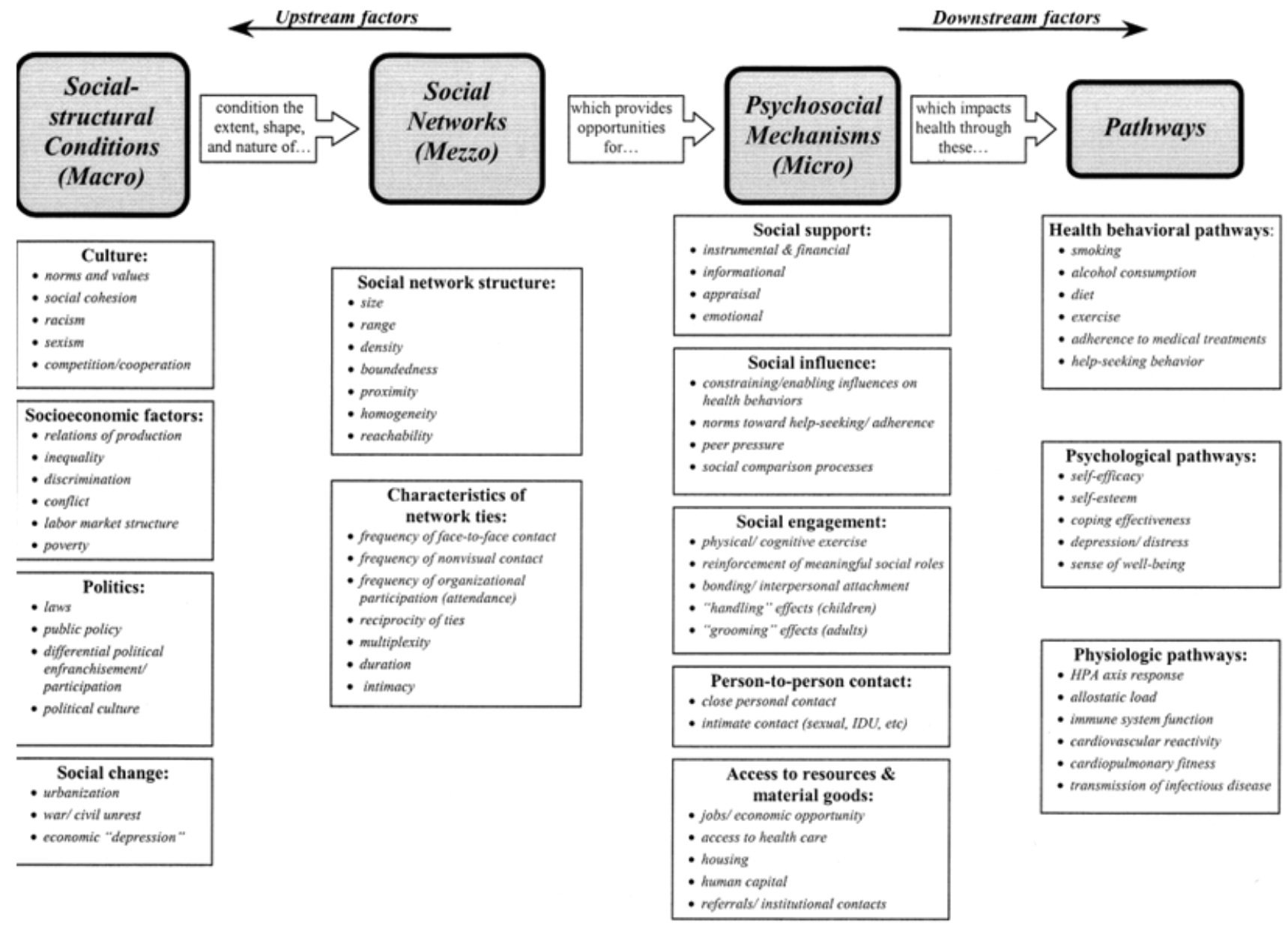

Figure I Upstream and downstream factors of health.

Reprinted from Social Science \& Medicine, 5 I (6), Berkman LF, Glass T, Brissette I, Seeman TE. From social integration to health: Durkheim in the new millennium, 843-857 (2000), with permission from Elsevier, Inc.

An example of such endeavors, which had a profound effect on the network development of community and migrant health centers in the United States, includes the public health initiative with the Pholela
Health Center (located in Umkomaas River Valley with the Zulu population) in Durban, South Africa in the 1940s and 1950s by Yach et al. ${ }^{4}$ Their initiatives established community-based multidisciplinary 
training. Pholela and other sites launched the development of centers for service, education, and research within their communities. They utilized an innovative approach to health disparities with a strong focus on social determinants. Their major contributions included: the utilization of sociological and anthropological methods in understanding health problems, emphasis on the importance of community diagnosis and participation, considerations of social and socio-structural conditions, and the view of health care as community action oriented care with emphasis on research programs that were based on responses of community needs.

Another example was the development of the Tufts Comprehensive Community Health Action Program in Bolivar County in Mississippi in 1966 with a population of 12,000 residents. ${ }^{5}$ In the 1960 s, there were no attempts in American history to conceptualize or utilize community health services for the poor. In Bolivar County, Black people in poverty, particularly the rural Black ex-sharecroppers and ex-plantation workers comprised the vast, silent majority of the community. The median annual family income was $\$ 900.00$ with four years of grade school as the highest education level. Most were unemployed, living in shacks with newspaper for insulation, and drank contaminated water from drainage ditches. Community organization at the Tufts-Delta Health Center based in Mound Bayou, Mississippi began in 1966, pioneered by Dr H Jack Geiger. ${ }^{6}$ Clinical health services began in late 1967 in a remodeled church. The combined programs of the health center, local health associations, the health council, and farm cooperative programs focused on every major problem affecting these residents. Ten local community health associations, each with its own community center and its own program linked with the health center was established. Every Black household in the county had at least one adult member participating in the decision making programs of a local health center and each health center had more than 6000 patient encounters. Incidences of infant mortality, infectious disease, and chronic illnesses decreased. Moreover, pathways to colleges and universities were created. To this day, the Tufts-Delta Health Center is owned and operated by the North Bolivar County Health and Civic Improvement Association, the community organization of poor people and poor communities.

These are two historic examples of how the lens of health disparity research widened to have a profound impact on what can be done to improve health outcomes not just locally, but nationally and internationally. From a social justice and economic standpoint, the lens of health disparity research is broader and requires multidisciplinary teams to tackle the upstream and downstream effects among various populations. Interventions to reduce health disparities integrate empowering efforts at the individual, social, community, state, national, and policy level. Both upstream and downstream approaches are needed. Community partners are crucial and participatory approaches essential. The lens of health disparity research requires a broad, multidisciplinary, community participatory view of what can be done to make a difference at the provider, community, state, national, and policy level. Albert Szent-Gyorgyi, a Hungarian biochemist and 1937 Nobel Prize winner for medicine, stated "research is to see what everybody else has seen and to think what nobody else has thought". ${ }^{7}$ The lens of health disparity research requires just that: innovative, creative, and transformational problem solving that goes beyond individual health in one moment of time.

\section{Acknowledgements}

None.

\section{Conflict of interest}

The author declares no conflict of interest.

\section{References}

1. National institute of health. HHS action plan to reduce racial and ethnic health disparities. Department of Health and Human Services. USA: Springer; 2001

2. Centers for disease control and prevention. CDC health disparities and inequalities report -United States, 2016. Morbidity and Mortality Weekly Report. 2016;65:1-69.

3. Berkman LF, Thomas G, Brissette I, et al. From social integration to health: Durkheim in the new millennium. Soc Sci Med. 200;51(6):843857 .

4. Yach D, Tollan SM. Public health initiatives in South Africa in the 1940s and 1950s: Lessons for a post-apartheid era. Am J Public Health. 1993;83(7):1043-1050

5. Jack Geiger H. Delta Health Center. Mound Bayous, USA: Springer; 2015.

6. Geiger HJ. Community-oriented primary care: A path to community development. American Journal of Public Health. 2002;92(11):1713-1716.

7. Brainy Quote. Albert Szent-Gyorgyi Quotes. McKinney, USA: Springer; 2017. 